\title{
Developing an institutional repository: experiences at the library, Faculty of Medicine, University of Jaffna
}

Murugathas, K. ${ }^{1}$ and Balasooriya, $\mathrm{H}^{2}{ }^{2}$

\begin{abstract}
Institutional repository is a network accessible database, with a set of services to capture, store, index, preserve and disseminates an institution's scholarly output in digital format. The main objective of the paper is to discuss the experiences in developing an institutional repository at faculty of medicine, university of Jaffna and suggestions to overcome the challenges. Further, to encourage the other universities in developing institutional repositories by emphasizing the benefits of an institutional repository in a university and also focuses on some key issues to be considered when developing a repository. The repository of university of Jaffna, faculty of medicine is functioning in the software D-Space with a dedicated server. Formulating collection policy, authority control of bibliographic details, checking the copyright policy and persuading the faculty members to deposit their publications were the major challenges focused in this study. More effort is needed to persuade researchers to deposit their publications. Librarians need to continue to educate them about the importance of institutional repository. Sharing experience in developing institutional repository would be useful to other universities.
\end{abstract}

Keywords: Institutional repositories, Research, University libraries,

DSpace, Open access

\section{Introduction}

An institutional repository is a digital collection of an institution's intellectual output. It is a new model for storing research output of a given institution. There are many definitions given by various experts. A University based institutional repository is a set of services that a university offers to the members of its community for the management and dissemination of digital materials created by the institution and its community members(Lynch, 2003).An institutional repository is a digital archive of the intellectual product created by the faculty, research staff, and students of an institution and accessible to end users both within and

Corresponding author:

${ }^{l}$ Senior Assistant Librarian, Faculty of Medicine, University of Jaffna, Sri Lanka.

Email:jaffnamed@yahoo.com

${ }^{2}$ Senior Assistant Librarian, Open University of Sri Lanka, Sri Lanka

Email: habala@ou.ac.lk 
Journal of the University Librarians Association of Sri Lanka, Vol.18, Issue 1, January 2014

outside of the institution with few if any barriers to access (Crow, 2002). It is a network accessible database with a set of services to capture, store, index, preserve and disseminates an institution's scholarly output in digital format. It is a tool for collecting, storing and disseminating information. Institutional repositories can be considered as a natural extension of an academic institution.

The main purpose of an institutional repository is to bring together, preserve and disseminate the intellectual output of an institution. Repositories involve change in the way research is disseminated, preserved and published. An institutional repository can serve as a publisher of research materials such as theses, peer reviewed papers, working papers, lecture notes, memorial lectures, keynote addresses and other types of grey literature.

The costs of the commercial software are not affordable by the librarians of academic institutions especially in the developing countries. The leadership of the Massachusetts Institute of Technology (MIT) collaboration with Hewlett Packard Company in the development of the D-Space institutional repository system is a model for many other universities. The software has also been released publicly under an open source arrangement, greatly lowering the cost and development barriers to implement repositories for other institutions. Though it is freely downloaded software, it requires some level of expertise to implement and maintain. The MIT software is not the only software available. There are many other open source software such as Fedora, E prints, Green stone etc. Institutional repositories emerged from universities but are spreading into other types of organizational institutions too.

Establishment of institutional repository especially in developing countries ensures that their national research becomes and contributes on an equal footing to the global knowledge pool (Anuradha, 2013).

\section{Why do we need an institutional repository?}

Research can only make an impact when other people can see its results. Researchers are awarded for their work not financially but through its impact. They want their research to 
Journal of the University Librarians Association of Sri Lanka, Vol.18, Issue 1, January 2014

be read, consumed and understood. They want their peers to comment on it, credit it and add or extend it. Researchers want to disseminate their research findings widely, but publishers restrict the access to publications based on subscription. Conventional method of research dissemination via publication in journals is much more limited in its possible impact than is the new method of publication of the same research in open access repositories. The conventional scholarly communication of journals limits, rather than expands the readership and availability of most scholarly research. Rounds of journal price increases and subsequent subscription cancellations act to reduce the audience further. In this context, the role of the institutional repository can break monopolies of the journal publishers and increasing the awareness of institutions intellectual output.

Most of the collections managed by our libraries are created outside the walls of our institutions.

What values are we giving the intellectual output created within the institution? They should be of greater importance to the future of our institution. It is the responsibility of the library professionals to collect, archive and widely disseminate the institution's intellectual output.

\section{Benefits of institutional repositories}

Collect and curate the digital outputs of the institution. Faculties are typically best at creating new knowledge. But not maintaining the record of this process of creation (Swan, 2011). If the whole research output is collected in the repository, the administrators can see what is being produced? By whom? When? Where outputs are being published?

- Under the current system of scholarly communication much of the intellectual output and value of an institution's intellectual property is diffused through thousands of scholarly journals. But institutional repository is a centralization and storage of all types of institutional output including unpublished or grey literature. Making it easier to demonstrate institutions scientific, social and financial value. 
- Showcase of the institution to the world and sell the institution to interested constituencies - prospective staff, prospective students and other stakeholders. It is an effective marketing tool for a university.

- Institutional repository serves as tangible indicators of an institution's quality thus increasing its worldwide visibility, prestige and public value (Crow, 2002).

- Institutional repositories can also play a very crucial role in higher education and in an

e-learning environment. Providing access to theses, dissertations and other research publications along with 'grey literature' which might otherwise be difficult to find. It facilitates further developments and sharing of digital teaching materials and aids.

- It is a research assessment tool. Repositories will be forming the base layer in the research assessment process. The success of an institution is to an extent judged by the volume and quality of research output. Research outputs are part of the product of a university (Holland\& Denning, 2011).

- Institutional repository can also be of great benefit to the improvement of university ranking especially the ranking systems which emphasize web presence and visibility. Webometrics considers four important factors to measure ranking of the universities. Which are Size (number of web pages), rich files (number of documents), scholars (number of papers) and visibility (number of external links) (Ahmad,Aquil \& Siddique, 2012).

- It will act as a self evaluation tool for management.

- Standardization of institutional records. Compilation of institutional curriculum vitae and individual curriculum vitae can be linked to the full text of articles.

- It enables long term preservation of scholarly work.

- Author's work is wider dissemination and more number of citations, rapid dissemination, personalized publication list and wider impact. Individual identification to the public.

- Easy and wider access to the research literature and avoiding unnecessary duplication are the major benefits to the research community. 
By considering all the above benefits, Institutional repositories are essential tools in Universities. But there are challenges to implement. The paper explores some of the issues and challenges the medical library, university of Jaffna experienced.

\section{Objective}

The main objective of the paper is to discuss the experiences in developing an institutional repository at the faculty of medicine university of Jaffna and suggestions to overcome the challenges. Further to encourage the other universities in developing institutional repository by emphasizing the benefits of it in a university and focuses on some key issues to be considered when developing an institutional repository.

\section{Methodology}

The IR project at the faculty of medicine, university of Jaffna was started in August 2013. The project was partially funded by World Health Organization. An expert in this field was invited for the initial customization and installation of this project. It is functioning in DSpace with a dedicated server. The web address of the IR is http: //repo.jfn.ac.lk. The database provides access to full text journal articles, abstracts, conference publications, abstract of theses, books and chapters in books, memorial lectures, past question papers, supportive study materials for learning such as practical manuals, learning objectives etc. and grey literature produced by the faculty members. The research publications were classified as sub communities based on the main disciplines in the medical curriculum. The database was first established locally then opened to the web.

\section{The challenges and experiences in developing an institutional repository}

Despite all the positive outcomes, developing a repository remains a challenge. The following are some of our experiences involved in developing an institutional repository.

\section{Information Communication Technology (ICT) knowledge}

ICT knowledge is a challenge to the library professionals. Library professionals must have quite enough knowledge on HTML language, installation \& customization of the D-Space 
Journal of the University Librarians Association of Sri Lanka, Vol.18, Issue 1, January 2014 according to the needs of the institution and the knowledge about the operating system. If the library does not have technical expertise in house, it is better to consult an expert in the field for the initial installation process in order to start the institutional repository. Proper maintenance of the server is essential to archive the data. Server is maintained by the ICT department in university of Jaffna. The ICT department is a key player in developing institutional repository in a University. Institutional repository can be integrated with other information systems available in the university. A good relationship has to be maintained with ICT department and institutional repository managers. Good knowledge on operating system and programming language are also needed to get the backup data from the institutional repository. ICT staff members enhance their competencies by knowing about the software, hardware and the networking facilities to make the repositories available to everyone. An effective institutional repository represents collaboration among librarians, information technologists and university \& faculty administrators (Lynch, 2003).

\section{Collection policy}

A repository must have a clear collection policy that defines what is acceptable in the repository. It includes the type of materials which is acceptable. Each institution defines its own policies dealing with access to and use of materials in repositories. Faculty can determine what contents merits inclusion.

\section{Collecting publications from the institutional members}

Although a few members appear to be enthusiastic in uploading the publications to the institutional repository many scholars in the institution are not interested in this. Faculty needs to be convinced that contributing to a repository will enhance their reputations in their disciplines and result in wider dissemination of their work. A successful institutional repository depends on the willingness of authors to deposit their work (Barwick \& Pickton, 2006). 
Journal of the University Librarians Association of Sri Lanka, Vol.18, Issue 1, January 2014

One of the major challenges is persuading the institutional members about the value of open access and potential of the institutional repository. It is the responsibility of the library professionals to persuade them about the value of institutional repository. As Grieg (2005) mentioned "the cultural change required to build a successful repository does not happen overnight. An advocacy campaign will require a significant amount of repetition and reinforcement of the message."

Some retrospective scholarly works were not archived by the researchers. In most instances, they have their list of publications but not the full text of the original publication. It has to be taken from authentic external sources to be included in the repository.

Faculty members are reluctant to spend time to convert their retrospective work from print to electronic which is in PDF format. The library facilitates the authors to submit articles either in print version or electronic version.

\section{Copyright policy}

It is necessary to check the publishers' policies. Faculty members generally have a misunderstanding about what rights an author has to their work after they have signed a copyright transfer agreement. Barwick (2007) stated that Vice Chancellor of Loughborough University endorsed a policy encouraging their staff to retain their copyright whenever possible.

A researcher uses the institutional resources such as equipments, fund, human resources, working hours, library resources and other resources. At the end, the institution is unable to access the final output unless the institution has enough money to subscribe the particular publication. A strong policy decision has to be formulated by the institution to add the publication to the institutional repository.

Researchers are more interested in reading full text than abstract or citations only (Bansode, 2011). Availability of full text in a repository is of great indicator of the success of institutional repository (Xia Jinfery \& Sun, 2013). Usability of an institutional repository 
Journal of the University Librarians Association of Sri Lanka, Vol.18, Issue 1, January 2014

relies on its content size and the value of the content is largely determined by the availability of full text documents (Arthur, 2006). Though some of our institutional publications are uploaded, only the abstract is there due to copyright issues. The faculty library maintains an in house database with all the full text articles. When a reader makes a request for full text by using the email given on the repository site, library will send the copy of the publication for the non-commercial use of the intellectual product.

\section{Standardization of the bibliographic data}

When uploading the information, standardization of bibliographic details is very important.

\section{Name of author}

Some individuals may publish their names in variety of formats. There are publications with different spellings for the same author. It accidentally occurs when there are many coauthors in publications. Example

Kamal Sandirasegarampillai, Kamal Santhirasegarampillai, Kamal Santhirasekarampillai, Kamal Sandiramsekarampillai,. K.Sandirasegarampillai

Some individuals may use different names at different stages of their life, such as before and after marriage. It is very important to maintain an authority file to the names of institutional members. Names with initials, dots and commas have to be used very consciously in order to make it easy for the users.

\section{Name of institution}

Similarly names of institutions are also standardized. Different publications give various shorten forms for the same institution. Example: WHO, World Health Organization. 


\section{Removal of duplicate records}

There are a few publications where same publication with different title representation; some publications have same title, initially published in a conference paper then published as journal article. It is better to manually identify and remove the duplicate records.

\section{Indication of superscript and subscript letters}

DSpace does not indicate the difference between superscript and subscript characters with the normal characters. It is quite difficult to enter the titles, which has chemical formulas. Example:

Aryl halide coordination to $\mathrm{Ru}(\mathrm{II})$ : crystal structure of mer, trans- $\left[\mathrm{RuCl}_{2}\left(\mathrm{PPh}_{3}\right)\left\{\mathrm{PPh}_{2} \mathrm{CH}_{2} \mathrm{C}\left(\mathrm{Bu}^{\mathrm{t}}\right)=\mathrm{N}-\mathrm{N}=\mathrm{CH}\left(\mathrm{C}_{6} \mathrm{H}_{3} \mathrm{~F}_{2}-2,6\right)\right\}\right]$

It appears on the repository as follows without indicating the differences between superscript and subscript characters, but the article in PDF format shows the proper title.

Aryl halide coordination to $\mathrm{Ru}(\mathrm{II})$ : crystal structure of

mer,trans- $[\mathrm{RuCl} 2(\mathrm{PPh} 3)\{\mathrm{PPh} 2 \mathrm{CH} 2 \mathrm{C}(\mathrm{But})=\mathrm{N}-\mathrm{N}=\mathrm{CH}(\mathrm{C} 6 \mathrm{H} 3 \mathrm{~F} 2-2,6)\}]$.

\section{Attitudes towards the self archiving}

One of the challenges comes from scholars' attitudes towards self-archiving. Many scholars have not been enthusiastic about self- archiving their research into repository as expected. The time required to upload a publication on the repository is a few minutes compared to the time and hard work spend to produce a manuscript. It is suggested that library can offer mediated service to the self archive model including undertaking any copyright checking. We are not asking faculty members to self- archive, all the work is being carried within the library. Libraries are themselves repositories, and have always dealt in the management of repositories for their users. (Johnson, 2002) 


\section{Making link to the staff profile}

The departments can directly link the staff profile of their website to full text of the relevant staff publications on the repository. The library copied the relevant URL address of the staff member from the repository and pasted them to a document. Then, faculty website administrator copied the URL prepared by the library and made the link. Repetition of copying and pasting activity led to missing of some characters in the URL and some of the links were not functioning properly. It was very time consuming to find out which characters were missing from the URL address. It is always advisable that; the website administrator directly gets a copy of the URL from the repository site to make the link.

\section{Sustainability}

Level of support by the institution is an essential factor in ensuring the sustainability of the institutional repository. Institutional repository is a long term commitment. Its maintenance must be an institutional strategic goal. The value of institutional repository should be explained in the new staff induction program. Regular lectures are organized by the staff development center of the university to persuade the staff members to submit their publications on the institutional repository. Continuous training in institutional repository is essential to make awareness in new developments to maintain a successful institutional repository. Back up of the data has to take place at regular intervals to adopt migration of data. The workload is incorporated into other workflows within the library.

\section{Conclusion}

Institutional repositories are essential tools for universities. It fulfils number of roles in a university. Open access repositories would broaden the usage. Knowledge may be expensive to generate, but it should be inexpensive to use. University libraries need to take positive initiation in developing repositories in order to widely disseminate the intellectual output of universities. In the competitive education market, institutional repositories provide a platform on which a university can showcase its research. Formulating collection policy, standardization of bibliographic details, checking copyright policy and persuading 
Journal of the University Librarians Association of Sri Lanka, Vol.18, Issue 1, January 2014 faculty members to deposit their publications were the major challenges focused in this paper. More difficult is the effort needed to persuade the researchers to deposit their publications. Success of institutional repository depends on the willingness of authors to deposit their work. Librarians need to continue to educate them about the importance of institutional repository. Its maintenance must be an institutional strategic goal. Sharing experience in developing institutional repository will be useful to similar universities in this region.

\section{References}

Ahmad, P., Aqil M and Siddique, M.A .(2012). Open institutional repositories in Saudi Arabia: Present and future prospects. International Journal of Digital Library Services, 2(2), 58-68.

Anuradha, K.T. (2013). Design and development of institutional repositories: a case study. The International Information. Library Review, 37(3), 169-178.

Arthur, S. (2006). The acquisition of open access research articles. Retrieved from http://eprints.utas.edu.au/388/01.

Bansode, S.Y.(2011). Developing institutional repository in university library: a case study of university of Pune. International journal of information dissemination and technology, 1(4), 188-192.

Barwick,J.P.L.(2007).Building an institutional repository at Loughborough university : some experiences. Program: electronic library and information systems, 41 (2), $113-123$.

Barwick, J. \& Pickton, M., (2006). A librarian's guide to institutional repositories. eLucidate, 3(2),3 - 9. Retrieved from https://dspace.lboro.ac.uk/2134/1122.

Crow,R.(2002). The case for institutional repositories: A SPARC position paper, Washington: The scholarly publishing and academic resources coalition.

Retrieved from http://www.arl.org/sparc/IR/IRFinal release102.pdf.

Grieg, Morag.(2005).Institutional advocacy campaign: guidelines and practical advice.DAEDALUS project: work package 3- advocacy, Retrieved fromhttps://dspace.gla.ac.uk/handle/1905/377. 
Journal of the University Librarians Association of Sri Lanka, Vol.18, Issue 1, January 2014

Holland.M \& Denning.T.(2011). Making the repository count: lessons from successful implementation. In university libraries and digital learning environments. Surrey:Ashgate.

Johnson, R. K. (2002). Institutional repositories: Partnering with faculty to enhance scholarly communication. D-Lib magazine,8:11. Retrieved from http://www.dlib.org/dlib/november02/johnson/11johnson.html.

Lynch,C.A.(2003).Institutional repositories: Essential infrastructure for scholarship in the digital age.ARL:abimonthlyreport,226:Feb,1-7.

Retrieved from http;//www.arl.org/newsltr/226/ir.html.

Swan, A.(2011). Institutional repositories - Now and next. In university libraries and digital learning environments. Surrey: Ashgate.

Xia Jingfeng \& Sun Li. (2007). Assessment of self archiving in institutional repositories: depositor ship and full text availability. Serials Review, 33 (1), 14-21. 